\title{
Are student exchange programs worth it?
}

\author{
Dolores Messer · Stefan C. Wolter
}

Received: 1 July 2005 / Accepted: 11 May 2006/ Published online: 8 July 2006

(C) Springer Science+Business Media B.V. 2006

\begin{abstract}
The number of university students participating in exchange programs has risen sharply over the last decade. A survey of Swiss university graduates (classes of 1999 and 2001) shows that participation in student exchange programs depends significantly on the socio-economic background of students. We further analyze whether the participants benefit from additional advantages caused by these exchange programs. Analyses show that student exchange programs are associated with higher starting salaries and a higher likelihood of opting for postgraduate degrees. Analyses using instrumental variable estimations (IV), however, show that these outcomes are not causally related to participation in exchange programs.
\end{abstract}

Keywords Exchange semester · ERASMUS · Graduate survey ·

Instrumental variables $\cdot$ Switzerland

JEL codes $\mathrm{I} 23 \cdot \mathrm{J} 24 \cdot \mathrm{J} 31 \cdot \mathrm{J} 44$

\section{Introduction}

Student mobility, or studying at universities other than the institution at which the student originally matriculated, was for a long time an important element in a fully rounded academic education. Then, in the latter decades of the 20th century, young people from a wider socio-economic background gained access to universities, student populations increased, the average duration of studies rose, and academic education became progressively "school-like". In association with these trends, the number of students choosing to spend their entire university education at their

D. Messer · S. C. Wolter

University of Bern, Bern, Switzerland

S. C. Wolter $(\bowtie)$

Swiss Coordination Center for Research in Education (SKBF), Entfelderstrasse 61, CH-5000

Aarau, Switzerland

e-mail: stefan.wolter@vwi.unibe.ch 
"home university" started to rise. Another factor contributing to this development was the reluctance of many universities to give their students academic credits for semesters spent at other universities. The resulting prolongation of the study period was a deterrent to many students who might otherwise have participated in an exchange program. In an attempt to break with this trend, many countries-especially in Europe-set up special programs to promote student mobility.

Though not an EU member state, Switzerland has participated in the EU's ERASMUS program since 1992. In accord with the goals of this program, the number of exchange students subsequently rose, as did the endeavors of Swiss universities to support the new mobility by making it easier for students to receive academic credit for classes taken at other universities. The students who primarily benefited from these new developments were those who had participated in an exchange program with a foreign university. The accreditation rate for semesters spent at non-Swiss universities rose from approximately 50\% in 1991 to approximately $75 \%$ in 2001 (see BBW, 2002, p. 9), a rate similar to the one for exchange semesters spent at other Swiss universities. The number of students spending at least one semester at another university during their studies virtually doubled from less than $15 \%$ to more than $25 \%$ in the period from 1991 to 2001 .

\section{Issues and objectives of the paper}

Given the sharp increase in the number of exchange-program students in recent years, the benefit derived by students from their added mobility merits investigation. Past surveys indicated that improving knowledge of foreign languages was a primary motivation for Swiss students in particular $(79.8 \%$ of Swiss respondents cited the language factor, see BBW, 2002, p. 7). A desire to improve their academic knowledge took second place $(69.8 \%)$. Establishing useful connections $(18.6 \%)$ was not (yet) considered important.

Despite these figures, an empirical analysis of the consequences of exchange semesters on a graduate's future academic career or labor market success has not been performed to date to our knowledge in Switzerland. And yet, an investigation into these issues should be of obvious interest given the level of public and private funding of exchange programs. In Switzerland, ERASMUS scholarships cover somewhat less than $20 \%$ of the expenses incurred during the exchange study period, more or less regardless of the students' destination (see BBW, 2002, p. 8).

The purpose of this study is to measure the impact of exchange programs on students' subsequent university education and their post-university career on the basis of two indicators. Among all the possible indicators available, it is necessary to choose the ones that are genuinely observable on the basis of empirical data. We assume that a semester spent at another university (regardless whether in Switzerland or in a foreign country) represents a positive input in building competencies (human capital) and that the benefits in this respect are greater than if the semester had been spent at the students' home university. This assumption is based on the reasoning that encountering the unfamiliar and establishing new personal and specialist contacts broaden one's horizon and enhance individual human capital in a manner that could not have been achieved by studying an additional semester at the university of matriculation. Based on this assumption, we can also expect in accordance with human capital theory that the enhanced human capital arising from a higher-quality education should have a 
positive impact on the young graduates' entry into the labor market. The latter can be measured on the basis of two factors: firstly, the probability of finding a job, and secondly, the starting salary, which in turn should be a reflection of the graduate's productivity (more on this in the following paragraphs). This paper focuses on the second factor, i.e. the starting salary, because the recruitment rate among Swiss university graduates - especially in comparison with other countries-is fairly high and it is somewhat hard to distinguish between voluntary and involuntary non-employment among those graduates who are not gainfully employed.

Some students who do not enter the labor market after their first degree go on to do postgraduate work. This gives us a second indicator in respect of which we would expect the same effect as with the starting salary. Enhanced human capital, more extensive experience and a larger network of contacts in the specialist field should—all other things being equal-help to convince professors that these students are more interesting candidates for postgraduate projects.

However, both these indicators only measure a fairly short-term potential impact of student exchanges and disregard the notion that exchange programs might also have positive effects in the longer term. One can nonetheless assume that any added specialist knowledge genuinely acquired by a student during an exchange program would have to become manifest within a short period of time in the form of quantifiable positive effects.

A causality problem is immediately apparent with regard to both parameters. Students who opt for an exchange semester are likely to generally differ from their non-mobile peers both in terms of motivation, ability, social background and other factors. Therefore, a potential impact of student exchange experience on salary level and the probability of doing postgraduate work cannot legitimately be causally attributed to the student exchange per se, because other differences between students may also produce these effects. As long as these differences are observable (in the data) we can control for these differences but some of these differences always remain non-observable. These non-observable differences can relate to the ability or the motivation of the graduates. Since it is impossible to rule out the possibility that - for instance - a higher probability of having a postgraduate degree is due not to the time spent studying at exchange universities but e.g. to a higher but unobservable baseline level of motivation among the students concerned, prompting them both to embark on an exchange program and write a doctoral thesis, it is important that these issues are not judged simply on the basis of a link (correlation) between the probability of an exchange program and the postulated effects. To address these issues and facilitate proper analysis, we employ additional instrumental variable estimations (so-called IV estimations; for a review of the method, see for example Angrist \& Krueger, 2001) to investigate the causal relationship between exchange experience and the outcome. Without wanting to go into any great methodological detail at this point, the challenge with this method is the necessity of finding a variable that is not in itself a potentially exogenous variable but rather is correlated with the independent variable (in our case, the semesters spent on exchange). If the explanatory variable thus "instrumentalized" still has a significant influence on the dependent variables, it is legitimate (in contrast to normal OLS or probit estimation) to assume not just a correlation but also a causal relationship between the variables. 


\section{Previous literature}

There exists a broad literature that was established mainly to analyze the effects of the ERASMUS program in Europe. The main body of this literature is centered around the work of researchers at the University of Kassel and a selection of the wide range of publications coming out of these projects have been consulted for the present study. The first studies aimed at giving a more detailed and accurate picture of ERASMUS student cohorts at the end of the 1980s and the beginning of the 1990s. These internationally comparative studies gave a comprehensive picture not only of the mobile students but also of their study programs and experiences abroad, the living conditions in the host countries, their motivation for studying abroad, their self-assessment of the academic progress and achievements abroad and much more (see e.g. Maiworm, Steube, \& Teichler, 1991, 1993b; Teichler, 1991, 1996; Teichler \& Maiworm, 1997). The studies included not only the views of students but also of their host organizations, teachers and the coordinators of the ERASMUS program (see e.g. Maiworm, Steube, \& Teichler, 1993a). These first studies were concentrated on the students that had taken part in the mobility program and in order to study the effects and the impact of these programs, the researchers had to rely mainly on the self-assessment of the students concerned.

In the late 1990s followed the CHEERS (Careers after Higher Education: A European Research Study) project that addressed some 36,000 persons 4 years after their graduation in 11 European countries and Japan (see e.g. Jahr, Schomburg, \& Teichler, 2002). As an improvement compared to the older surveys the data was now based on a general survey of graduates, which allowed the constitution of a comparison group of non-mobile students to the mobile students.

Some of the major findings of the mentioned studies are of importance for the present study and are therefore taken up again, although sometimes in a different form and with different statistical methods:

- The previous studies have found that in general the mobile students present a "fairly select group as compared to the average students..." (Teichler \& Jahr 2001, p. 447), which suggests that the selection of students into mobility programs should be taken into account when trying to analyze the effects of these programs. In order to do so we use statistical methods that control for observable and non-observable differences between mobile and non-mobile students.

- Most studies found that mobile students were convinced that their knowledge was improved through student mobility. Therefore we think that it is legitimate to test whether the mobile students also have an advantage in their professional and academic career when compared to non-mobile students.

- In practically all the surveys, students and graduates rated the importance of salaries as a motive for being mobile as rather low and they also self-assessed the relative advantage in earnings due to the mobility semesters as inexistent or also rather low. In the light of these findings, the choice of the entry salary as one of the impact variables of mobility semesters in this study needs further explanation (see the following paragraph).

- In the assessment of the impacts of student mobility, the cited studies rely almost exclusively on the self-assessment of the mobile students. Contrary to this kind of analysis we try in this paper to use criteria that are on the one hand as objective 
as possible ${ }^{1}$ and on the other hand easily comparable between mobile and nonmobile students. This allows an assessment of the potential relative benefits of student mobility.

- Most of the literature on student mobility concentrates on international mobility (and as such focus on the ERASMUS program). In the present study, we have included internationally and nationally mobile students independent of the mobility program in order to get a broader picture of the potential benefits of mobility.

- Last but not least, there are of course aspects of mobility during the course of the study that were investigated by previous studies and that cannot be replicated in the present study. As an example one could mention the analysis of the impact of student mobility on professional mobility after graduation (see Teichler \& Maiworm, 1994 or Teichler \& Jahr, 2001). Although the majority of formerly mobile students are employed at home, the study abroad - according to this study - triples the likelihood of being employed abroad. If working abroad is a motive for studying abroad (which we can assume), then of course a potential benefit of mobility is missing in the present study. However, the cited studies did not investigate whether the correlation between studying abroad and being employed abroad is of causal nature. One could also easily assume that students that wish to work abroad after graduation are more likely to spend some of their study time abroad.

\section{Why salaries?}

One particular feature of this paper needs specific attention and perhaps explanations: As mentioned in the previous paragraph, subjective assessments of students and graduates have always shown that the salary obtained after graduation is hardly ever mentioned as an important motive for studying in an other university or abroad. This finding in itself is not surprising and most researchers take it as a sufficient argument not to investigate potential earnings effects further. In our view there are at least three reasons for analyzing these effects, despite the apparent disinterest of students (and researchers). Firstly, students, when surveyed, mention motives for external semesters, like improving their language skills or broadening of their academic knowledge, that should have also - in the eyes of prospective employers-have a positive impact on the graduates' productivity and thus on their salaries. Therefore, regardless of the question whether an improved salary was the primary motive for the mobility semesters or not, we can expect that mobility semesters have a positive impact on the salary. Secondly, we should not attribute too much importance to selfdeclared motives in surveys as they are likely to be biased by socially desirable patterns of answers. That this can be the case in this context is obvious and an observation described by Wolter and Zbinden (2002) illustrates this. In a large survey on wage expectations of Swiss university students, this study found that, when asked directly about the importance of salaries for studying, the majority of students rated this importance very low. However, the study also found that students that rated their own ability above the average of all students also expected salaries that were

\footnotetext{
1 Objective in this context means that we can assume that the answers of graduates in the graduate survey to the questions of "entry salary" and whether they are currently writing a PhD thesis are not biased by the fact that some of the graduates were mobile as students and others not.
} 
significantly above the salaries indicated by those students that had rated themselves less favorably. This observation shows that even if the salary itself might not be the primary motive to invest more or less in the study program, students expect that improvements in their ability will be reflected on the level of the salaries they are going to earn. The same reasoning could be applied to the question of investments in mobility semesters. Thirdly, as a part of the costs of the mobility semesters is borne by the tax payer, it could be of general interest whether these expenses are just a subsidy for individual consumption or an investment. In order to be considered as an investment, the mobility semesters would have to improve the skills of the mobile students and thus their salaries. Higher salaries would then lead to higher taxes paid by those graduates and thereby repayment of the earlier contribution of the state to the mobility costs. Of course one could argue that the society benefits also in other ways from the mobility of students. But in this case these external benefits would have to be proven first, as much as the effects analyzed in this study.

A remaining question might be whether "starting salaries" is a meaningful variable to measure the impact of student mobility on the productivity of graduates. To this question, we offer three arguments in favor of entry salaries. Firstly, entry salaries show a considerably high variance that is not just random but can be explained to a certain degree by the study behavior of graduates. Therefore it is interesting to know whether mobility during the course of study also helps to explain a part of this variance. Secondly, as mentioned earlier, if we expect mobility to be beneficial for the productivity of the graduate, this should already be reflected in the entry salaries. Thirdly, when using salaries that are earned later in the professional career one creates a causal distance between the cause (mobility) and the effect (salary) and it is therefore even more difficult to assert with certainty that a measured correlation between the two is truly causal.

\section{Data}

All of the data used here is taken from two rounds (1999 \& 2001) of surveys among Swiss university graduates. This survey is a full census and has been performed every two years since 1977 and data is available since 1981. Graduates from Universities of Applied Sciences have been surveyed since 1993, but this subset of data is not of primary interest here in view of the particular hypothesis we are investigating. Although the basic elements of the questionnaires have remained unchanged since the beginning, a number of important questions were included only in the latter rounds. Our investigation therefore does not include older rounds of surveys. Finally, although the 2003 survey has been conducted and the overall results have been published, the authors did not have access to the micro-dataset at the time of researching this paper.

Graduates are contacted in written form approximately 1 year after having completed their studies. Among other things, the questions elicit information on their transition to the labor market, their first job or their continuing academic studies (e.g., PhD studies). Respondents are also asked to provide information on study patterns, which can be used to trace their study career (at least to some extent).

The dataset used here pools data from the 1999 and 2001 survey rounds in order to have a population large enough to investigate the variable that interests us most 
(exchange semesters). The pooling of two surveys is taken into account in the regressions by the use of a dummy for the year of graduation.

Three important organizational aspects of university studies in Switzerland have been addressed in a specific form during the subsequent processing of the data and the analysis. Firstly, a number of university degree programs have a fairly rigid, school-like structure (as medicine or technical studies). Students in these degree programs have little or no freedom of choice in planning their studies. Deviations from the regular study period or internal structure of the study program are therefore not possible (with the exception that if a student fails exams he or she has to repeat one or more years of study). With regard to degree programs of this kind, therefore, variation in terms of study behavior has little to do with individual study planning. Although exchange semesters may occur in degree programs of this nature, they are-practically out of necessity-organized to dovetail with the curriculum of the home university or may in certain instances be compulsory; as such, these exchange semesters and their implications are less interesting than modular degree programs with a selection of electives. Accordingly, rigid degree programs of this kind were not included in the sample for the time being.

Secondly, as already mentioned, some exchange semesters may not be accredited or recognized by a student's home university. This may have to do with the home university's policy. It may also be due to the students' choice of host university. For example, if learning a foreign language or simply getting to know a specific country is considered more important, students might intentionally choose not to study subjects matching their primary university's curriculum when deciding where to spend an exchange semester. Since we cannot assume that accredited semesters at a host university will have exactly the same impact on a student's employment and study career as the aggregate of all exchange semesters, all the analyses were also conducted separately using only the data from the accredited semesters. In qualitative terms, however, it transpires that the outcomes in either case are ultimately fairly identical.

Finally, a distinction is made between internal and external mobility, the former referring to mobility between different Swiss universities and the latter to exchange programs with foreign universities. Separate analyses of internal and external mobility disclosed no meaningful differences in the empirical analysis, however. Therefore, in order to achieve the largest possible number of observations, separate analysis was not performed. Consequently, the exchange semester variable includes both forms of student mobility.

\section{The first descriptive analyses}

The dataset employed comprises 3,586 observations. ${ }^{2}$ Eight hundred and thirty seven $(23.3 \%)$ of the graduates surveyed said that they had participated in exchange programs during their time at university. Six hundred and fifty one of the 837 received academic credits for their time spent on exchange, corresponding to an accreditation rate of approximately $78 \%$ in this sample. $60 \%$ of these exchange semesters were at other Swiss universities and $40 \%$ at universities abroad.

\footnotetext{
${ }^{2}$ The following analyses relate only to university graduates receiving their first degree. Second degrees or postgraduate degrees have not been included owing to their non-comparability with graduates getting their first degree.
} 
The results of an initial probit estimation (see Table 1) show the characteristics of students who spent time on exchange. This first descriptive analysis shows that there is no gender-related difference predicting which students are likely to opt for an exchange program. However, there are very definite socio-economic variables and other background features, which are significant predictors of student mobility; this agrees with statistics from other countries (see e.g. ADMIT, 2002). One significant variable in this regard relates to whether the student attended university in the canton where his or her parents reside ("resides in university canton"). This variable displays a significant negative correlation with the probability of participation in an exchange program. The effect is amenable to two different interpretations, which, however, are not mutually exclusive. On the one hand, students who do not study in the canton where their parents are based have already displayed some mobility in terms of their choice of home university. In that respect, a decision to spend one or more semesters at another university is probably fairly immaterial to them. Economically speaking, the marginal cost of an exchange program for these students would be virtually zero. On the other

Table 1 Probit analysis, dependent variables: exchange semesters

\begin{tabular}{|c|c|c|c|c|}
\hline \multirow[t]{2}{*}{ Independent variables } & \multicolumn{2}{|l|}{ All semesters } & \multicolumn{2}{|c|}{ Accredited semesters } \\
\hline & Coefficients & $\begin{array}{l}\text { Marginal } \\
\text { effects }\end{array}$ & Coefficients & $\begin{array}{l}\text { Marginal } \\
\text { effects }\end{array}$ \\
\hline Female & 0.091 & 0.026 & 0.067 & 0.016 \\
\hline Swiss & $-0.238 * *$ & -0.074 & $-0.256 * *$ & -0.068 \\
\hline Age starting university & $-0.421 * *$ & -0.121 & $-0.411 * *$ & -0.100 \\
\hline Age starting university (squared) & $0.007 * *$ & 0.002 & $0.006 * *$ & 0.002 \\
\hline Resides in university canton & $-0.296 * *$ & -0.085 & $-0.300 * *$ & -0.071 \\
\hline Mother's educational level ${ }^{\mathrm{a}}$ & $0.275^{* *}$ & 0.086 & $0.273 * *$ & 0.073 \\
\hline 2001 survey & -0.073 & -0.021 & -0.042 & -0.010 \\
\hline $\begin{array}{l}\text { Gainfully employed while studying } \\
\text { (unrelated only) }\end{array}$ & 0.052 & 0.015 & 0.030 & 0.007 \\
\hline $\begin{array}{l}\text { Gainfully employed while studying } \\
\text { (related only) }\end{array}$ & 0.041 & 0.012 & 0.063 & 0.015 \\
\hline $\begin{array}{l}\text { Gainfully employed while studying } \\
\text { (related and unrelated) }\end{array}$ & $0.191 *$ & 0.056 & 0.191 & 0.047 \\
\hline Vocational apprenticeship before university & $0.328 * *$ & 0.105 & $0.312 *$ & 0.085 \\
\hline $\begin{array}{l}\text { Degree qualifying for secondary } \\
\text { school teaching }\end{array}$ & 0.082 & 0.024 & 0.030 & 0.007 \\
\hline Constants & $5.926 * *$ & & $5.430 * *$ & \\
\hline Controls for university and field of study & YES & & YES & \\
\hline Log likelihood & -1753.15 & & -1533.70 & \\
\hline LR $\operatorname{chi}^{2}(26)$ & 383.53 & & 321.06 & \\
\hline Observed probability & & 0.233 & & 0.181 \\
\hline Estimated probability & & 0.209 & & 0.157 \\
\hline$N$ & 3586 & & 3586 & \\
\hline Pseudo $R^{2}$ & 0.10 & & 0.09 & \\
\hline
\end{tabular}

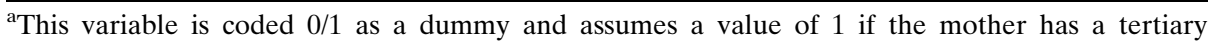
education. Although detailed information about the education of mothers is available, this $0 / 1$ specification has the highest predictive value in the regressions shown

b"Related" or "unrelated" tells whether the job engaged in during university was or was not related to the subjects studied. The reference group comprised those graduates who said they had not been gainfully employed at any time during their studies

$*$,** stand for a level of significance of $95 \%$ and $99 \%$, respectively 
hand, this variable might be a sign of a student's socio-economic status, because a lack of financial resources may be the reason why the student has chosen a university in his or her home area in the first place. ${ }^{3}$ In such cases, the probability of engaging in an exchange program is, of course, reduced because a not insignificant share of the costs incurred during an exchange program is privately funded.

"Mother's educational level" is another significant variable. The latter variable is the best marker for the educational background of the student's family, as having a mother with a tertiary education is a very good indication that both parents are university graduates. ${ }^{4}$

The student's age when starting university is another factor impacting on student mobility (the older the student, the lower the probability of participating in an exchange program). The probability of going on exchange rises if students have already completed a professional/vocational education program when they matriculate (the "vocational apprenticeship before university" variable). The latter is difficult to explain at first sight.

\section{Empirical analysis}

The empirical analysis investigates the effects and consequences that student mobility exchange programs can have on the academic and professional biographies of the students. We initially also focused on the question whether a semester (or several semesters) spent in a mobility program had any influence on the overall period of time studied. Due to a change in the questionnaire between 1997 and 1999 and because the question about the study-length is imprecise and the answers therefore difficult to interpret, we choose not to analyze this question further.

To test the impact of student mobility on the study outcome, we analyzed the influence of exchange semesters on two tangible facts: starting salaries and subsequent academic careers. The starting salary is arguably a better indicator for this purpose than later salary data because the competency advantages acquired through participation in exchange programs should actually pay off immediately, meaning when these students enter the labor market. As a means of depicting the subsequent academic career, we selected whether the students wrote a dissertation after obtaining their first degree as the indicator.

\section{Starting salary when entering the labor market}

Table 2 presents the results of the salary regressions. The sample comprises only those students who entered the labor market directly after graduation. Not included

\footnotetext{
${ }^{3}$ There is research evidence that students from low-income families are particularly disadvantaged by distance to the university (see e.g. Frenette, 2006). In our case this means that those students who do not study in the canton of their origin are more likely to come from a high-income family than the students studying at their "home" university.

${ }^{4}$ Only about one-third of fathers with an academic degree are married to a woman with an academic degree. The inverse ratio applies in the case of women: $80 \%$ of women with an academic degree are married to a man with an academic degree. The figures are due, firstly, to differences in marriage patterns between the genders (see Behrmann \& Rosenzweig, 2002 and others) and, secondly, to the fact that the percentage of female university graduates was still very low in the parent generation of the students analyzed here.
} 
Table 2 OLS estimation, dependent variables: Salary (logarithmized)

\begin{tabular}{|c|c|c|}
\hline \multirow[t]{2}{*}{ Independent variables } & \multicolumn{2}{|c|}{ Number of semesters } \\
\hline & All & Accredited only \\
\hline Exchange semesters (all) & $0.033^{*}$ & \\
\hline Exchange semesters (accredited only) & & 0.015 \\
\hline Number of semesters (all) & $0.005^{* *}$ & \\
\hline Number of semesters (accredited only) & & $0.005^{*}$ \\
\hline Female & $-0.032 * *$ & $-0.032 * *$ \\
\hline Swiss & 0.010 & 0.010 \\
\hline Age starting university & $0.059 * *$ & $0.052 * *$ \\
\hline Age starting university (squared) & $-0.001 *$ & -0.001 \\
\hline Resides in university canton & 0.008 & 0.008 \\
\hline 2001 survey & $0.023^{*}$ & $0.023 * *$ \\
\hline Works part-time & 0.020 & 0.020 \\
\hline Still has a secondary occupation & $-0.030 *$ & $-0.030 *$ \\
\hline Employment contract is temporary & $-0.050 * *$ & $-0.049 * *$ \\
\hline Working on a dissertation & 0.030 & 0.029 \\
\hline A degree in respective field of study was required & $0.033^{* *}$ & $0.034 * *$ \\
\hline No degree required for employment position ${ }^{\mathrm{a}}$ & $-0.087 * *$ & $-0.087 * *$ \\
\hline Gainfully employed while studying (unrelated) & -0.028 & $-0.029 *$ \\
\hline Gainfully employed while studying (related) & 0.010 & 0.010 \\
\hline Gainfully employed while studying (related \& unrelated) & $-0.030 *$ & $-0.030 *$ \\
\hline Vocational apprenticeship before university & $-0.070 * *$ & $-0.068 * *$ \\
\hline Degree qualifying for secondary school teaching & $0.112 * *$ & $0.111 * *$ \\
\hline Constants & $7.800 * *$ & $7.900 * *$ \\
\hline $\begin{array}{l}\text { Controls for university, field of study, canton of residence } \\
\text { and field of employment }\end{array}$ & Yes & Yes \\
\hline$F(50,1900)$ & 14.22 & 14.03 \\
\hline Prob $>F$ & 0.000 & 0.000 \\
\hline$N$ & 1951 & 1951 \\
\hline Adjusted $R^{2}$ & 0.253 & 0.251 \\
\hline
\end{tabular}

${ }^{a}$ Reference groups are graduates who were required to have a university degree but not in a specific field of study

*** stand for a level of significance of $95 \%$ and $99 \%$; respectively

in the sample are those graduates who were unemployed or not gainfully employed, those who pursued another full-time education program without pay and those graduates who did not pursue regular employment but instead, for example, worked as an intern or trainee. Inclusion of these graduates would have led to an excessive distortion of the salary data.

The results derived from all exchange semesters show that there is a slight salary advantage of $3.3 \%$ with regard to the starting salary. ${ }^{5}$

\footnotetext{
${ }^{5}$ We also tested the possibility that the exchange semesters not only had a direct impact on salary but also indirectly on the quality of the employment position acquired by a graduate. In order to test this, we estimated a regression in which we did not impute all characteristics of an employment position (temporary, degree required, part-time, etc.) as independent variables. In such a regression the salary-enhancing effect of exchange semesters rises from $3.3 \%$ to $4.1 \%$. Taking into consideration only the recognized exchange semesters raises the salary effect from $1.5 \%$ to $2.6 \%$ and becomes significant at a level of $5 \%$. One can thus assume that a small share of the positive salary effect of mobility semesters is taken into consideration in the variables, which describe the quality of the employment position and that graduates with exchange semester experience are more likely to obtain good jobs than other graduates. In the instrumental variable regression, however, the results are not qualitatively affected by this specification.
} 
If, however, only those exchange semesters that were also accredited by the home university are taken into consideration, no significant salary advantage is discernible. The remaining variables reveal the generally expected, and in specialist literature often cited, relationships, for example, a slight "salary discrimination" of women is observed or that temporary contracts pay a significantly lower salary.

Another expected outcome is that employment positions that required a degree in the respective field of study exhibited a salary advantage while employment positions that did not require any university degree whatsoever offered significantly lower salaries (see for example Groot \& Massen van den Brink, 2000).

Despite the positive influence exchange semesters have on starting salary (in the specification "all exchange semesters"), the question arises whether this can be interpreted in a causal sense or whether this advantage is because the students who participate in an exchange program differ from the other students due to unobservable characteristics that also have an influence on salary. If the latter were to be the case, then the students participating in an exchange program would also earn more even if they did not study at another university and, conversely, students without exchange semester experience would not have a higher starting salary even if they had participated in an exchange program.

In order to clarify the question of the causality of exchange semesters, we instrumented the "exchange semester" variable, selecting the educational level of the graduates' mothers as the instrument. This means we utilize the factor that the mother's level of education has a significant influence on whether a student spends a semester studying at a host university or not (see Table 1) and yet at the same time has no direct influence on starting salary after graduation. The additional condition that the instrumental variable does not correlate with the unobservable factors must, however, be assumed and cannot be directly tested (see for example Wooldridge, 2003, p. 484ff). ${ }^{6}$

The results of the two instrumental variable estimations are presented in Table 3. The results show that the influence of the exchange semesters is not significant in either case if the exchange semester variable is instrumented. A causal and positive influence of exchange semesters on salary can therefore not be confirmed.

\section{Probability of writing a dissertation}

Conducting the same analysis with respect to the probability of commencing dissertation research after graduation, a positive correlation between exchange semesters (total) and the probability of writing a dissertation can be established for the simple probit estimation (see Table 4). Exchange semesters would raise the roughly $20 \%$ share of graduates who begin to work on a dissertation after obtaining their first degree by 3.8 percentage points. No significant connection can be established, however, with regard to the specification in which only accredited exchange semesters are imputed.

\footnotetext{
6 There is some critique in the literature that the educational level of the mother might well be correlated with unobservable factors and this would make this variable an invalid instrument. We, therefore, also used the variable "resides in the university canton" as an alternative instrument. The analysis, not reported here, shows qualitatively the same result. Once the dummy for exchange semesters is instrumented with the variable "resides in the university canton", the correlation between this variable and the outcome is - as in Table 3-not significant any longer.
} 
Table 3 IV (2SLS)—estimation, dependent variable: Salary (logarithmized) exchange semester instrumented

\begin{tabular}{lll}
\hline Independent variables & \multicolumn{2}{l}{ Number of semesters } \\
\cline { 2 - 3 } & All & Accredited only \\
\hline Exchange semesters (all) & -0.052 & \\
Exchange semesters (accredited only) & & -0.058 \\
Number of semesters (all) & 0.008 & \\
Number of semesters (accredited only) & & 0.008 \\
Female & $-0.030^{*}$ & $-0.031^{* *}$ \\
Swiss & 0.004 & 0.003 \\
Age starting university & 0.040 & 0.037 \\
Age starting university (squared) & -0.000 & -0.000 \\
Resides in university canton & 0.007 & 0.007 \\
2001 survey & $0.023^{*}$ & $0.023^{*}$ \\
Works part-time & 0.018 & 0.017 \\
Still has a secondary occupation & $-0.029^{*}$ & $-0.029^{*}$ \\
Employment contract is temporary & $-0.049^{* *}$ & $-0.049^{* *}$ \\
Is working on a dissertation & 0.035 & 0.034 \\
A degree in respective field of study was required & $0.034^{* *}$ & $0.035^{* *}$ \\
No degree required for employment position & $-0.091^{* *}$ & $-0.091^{* *}$ \\
Gainfully employed while studying (unrelated) & $-0.030^{*}$ & -0.032 \\
Gainfully employed while studying (related) & 0.012 & 0.011 \\
Gainfully employed while studying (related \& unrelated) & -0.028 & -0.030 \\
Vocational apprenticeship before university & $-0.063^{*}$ & -0.06 \\
Degree qualifying for secondary school teaching & $0.111^{* *}$ & $0.012^{* *}$ \\
Constants & $8.068^{* *}$ & $8.097^{* *}$ \\
Controls for university, field of study, canton of & Yes & Yes \\
residence and field of employment & & \\
$F$ (50,1900) & 13.79 & 13.77 \\
Prob > F & 0.000 & 0.000 \\
$N$ & 1951 & 1951 \\
Adjusted $R^{2}$ & 0.239 & 0.235 \\
\hline
\end{tabular}

$*, * *$ stand for a level of significance of $95 \%$ and $99 \%$; respectively

In contrast to the salary regression, we cannot apply the "mother's educational level" variable as an instrument because this has a direct influence on the probability of starting a dissertation. ${ }^{7} \mathrm{We}$, therefore, used the variable "Resides in university canton" as the sole instrument. This variable fulfils the qualities of an instrumental variable because it influences the probability of studying in an exchange program (see Table 1) but it does not directly influence the probability of writing a dissertation. These connections can be theoretically explained relatively easily. Firstly, it is clear that students who decide to study at the university closest to their parent's place of residence already express a certain degree of restricted mobility. Secondly, it is not assumed that this possibly financially induced immobility during their studies would have an effect on the probability of their writing a dissertation, one reason being that a dissertation is generally accompanied by a paid university position as an assistant and, therefore, a dissertation should not be precluded by primarily financial considerations.

\footnotetext{
${ }^{7}$ A socioeconomic "preferential treatment" of students with regard to the continuation of scientific careers has already been established in earlier studies (see for example Leemann, 2002). This study also discovered a lower participation rate among women, a result that is again confirmed here. 
Table 4 Probit estimation, dependent variables: Dissertation (marginal effects)

\begin{tabular}{lll}
\hline Independent variables & \multicolumn{2}{l}{ Number of semesters } \\
\cline { 2 - 3 } & All & Accredited only \\
\hline Exchange semesters (all) & $0.038^{*}$ & \\
Exchange semesters (accredited only) & & -0.021 \\
Number of semesters (all) & $-0.013^{* *}$ & \\
Number of semesters (accredited only) & & $-0.014^{* *}$ \\
Female & $-0.067^{* *}$ & $-0.067^{* *}$ \\
Swiss & $-0.100^{* *}$ & $0.099^{* *}$ \\
Age starting university & $-0.054^{*}$ & $-0.059^{*}$ \\
Age starting university (squared) & 0.001 & 0.001 \\
Mother's educational level & $0.064^{* *}$ & $0.064^{*}$ \\
2001 survey & -0.000 & -0.000 \\
Gainfully employed while studying (unrelated) & -0.018 & -0.018 \\
Gainfully employed while studying (related) & -0.008 & -0.008 \\
Gainfully employed while studying (related \& unrelated) & -0.028 & -0.028 \\
Vocational apprenticeship before university & $0.078^{*}$ & $0.080^{* *}$ \\
Degree qualifying for secondary school teaching & $-0.074^{*}$ & $-0.074^{*}$ \\
Controls for university and field of study & YES & YES \\
Log likelihood & -1581.63 & -1580.89 \\
LR chi ${ }^{2}$ (29) & 437.49 & 438.96 \\
Observed probability & 0.201 & 0.201 \\
Estimated probability & 0.175 & 0.175 \\
$N$ & 3589 & 3589 \\
Pseudo $R^{2}$ & 0.122 & 0.122 \\
\hline
\end{tabular}

*** stand for a level of significance of $95 \%$ and $99 \%$, respectively

Table 5 lists the estimations with the instrumented variables for exchange semesters. The results do reveal a strong but no longer significant relationship between the exchange semesters and the probability of commencing dissertation research. The significance is, despite the high coefficients, no longer given because the standard error has also increased considerably in the regression with instrumental variables. Accordingly, however, the correlation between exchange semesters and the probability of beginning a dissertation can no longer be interpreted in a causal sense. Expressed differently, one can assume that the probability of writing a dissertation would still be higher among the exchange students even if they had not participated in any student mobility program. Conversely, the probability of writing a dissertation among those students who did not participate in an exchange program would not be positively influenced.

\section{Conclusions}

The study presented in this article investigates to what extent an exchange semester may affect the academic and professional career of university graduates. Starting from the observation that the popularity of exchange programs at domestic and foreign universities has grown considerably in recent years, also in Switzerland, and that universities have made accordingly extensive efforts to attract students from 
Table 5 IV probit estimation, dependent variables: Dissertation, exchange semester instrumented (marginal effects)

\begin{tabular}{lll}
\hline Independent variables & \multicolumn{2}{l}{ Number of semesters } \\
\cline { 2 - 3 } & All & Accredited only \\
\hline Exchange semesters (all) & 0.301 & \\
Exchange semesters (accredited only) & & 0.381 \\
Number of semesters (all) & -0.023 & -0.024 \\
Number of semesters (accredited only) & & $-0.068^{* *}$ \\
Female & $-0.071^{* *}$ & -0.073 \\
Swiss & -0.081 & 0.012 \\
Age starting university & -0.009 & -0.000 \\
Age starting university (squared) & 0.000 & 0.045 \\
Mother's educational level & 0.046 & -0.001 \\
2001 survey & 0.000 & -0.015 \\
Gainfully employed while studying (unrelated) & -0.016 & -0.009 \\
Gainfully employed while studying (related) & -0.07 & -0.032 \\
Gainfully employed while studying (related \& unrelated) & -0.032 & 0.045 \\
Vocational apprenticeship before university & 0.053 & $-0.079 *$ \\
Degree qualifying for secondary school teaching & $-0.079 *$ & YES \\
Controls for university and field of study & YES & 1581.35 \\
Log likelihood & -1583.73 & 438.05 \\
LR chi ${ }^{2}$ (29) & 433.29 & 0.201 \\
Observed probability & 0.201 & 0.175 \\
Estimated probability & 0.175 & 3589 \\
$N$ & 3589 & 0.122 \\
Pseudo $R^{2}$ & 0.120 & \\
\hline
\end{tabular}

*,** stand for a level of significance of $95 \%$ and $99 \%$; respectively

other universities, the question as to the benefits students may reap from this mobility certainly merits closer attention.

Starting salaries upon entry to the labor market and the probability of writing a dissertation were examined as possible expressions of the benefits deriving from exchange semesters. Both forms of a potential benefit are based on the hypothesis that students participating in exchange programs acquire more, or a different quality of human capital than if they had spent this time at their home university and that they consequently have potentially better prospects both in the labor market and in the university environment. The hypothesis is backed up by the self-assessment of the academic qualifications acquired abroad by graduates surveyed in previous studies on ERASMUS students.

The empirical analysis indicated for both forms of the potential benefit of exchange semesters that they correlate positively and significantly with student mobility when all exchange semesters are imputed and not just those semesters that have been accredited by the home universities. The finding of a positive correlation between mobility and entry salaries contrasts the findings of previous studies that relied on the self-assessment of mobile students and which had not found positive impacts on graduates' earnings. An explanation for this difference might be that when students are directly asked to subjectively assess the impacts of mobility on a specific outcome, the answers might be biased by higher expectations of the more mobile students.

The testing of the causality of these relationships via instrumental variable estimations indicates, however, that none of these correlations can be interpreted 
as having a causal role. In other words, one would have established salary advantages and a greater probability of embarking on a dissertation among these graduates even if they had not participated in any exchange programs. This indication, in connection with the observation that it is only in the specification "all exchange semesters" that the significant correlations between exchange semesters and the said effects were seen, suggests that the characteristics of graduates who chose to participate in an exchange program, more or less regardless of whether the exchange semester was accredited by the home university or not, are simply better. Accordingly, the advantages these graduates have in the labor market and their subsequent scientific or academic career are simply attributable to the better capabilities of these graduates and not to the fact that they have studied in an exchange program.

Does this mean that exchange semesters are not worthwhile? No, because students also derive other benefits from exchange programs that have not been examined in this study. It is well possible that student mobility increases the awareness of cultural differences and other things and that these effects generate a private and social return not covered by the present analysis.

However, one can probably go so far in the analysis of these results as to establish that the personal gain must be so high that it is capable of compensating for the personal costs of exchange semesters because no directly realizable gain in the labor market or subsequent academic pursuits is derived as a result of this exchange experience. From an organizational/political point of view, one might ask whether the financial support given to exchange programs is justified under these circumstances. Two aspects must be critically examined in this regard. First, the public funding can be questioned if it ultimately represents subsidization of a personal "consumption benefit" that does not actually serve the enhancement of the productive potential of the student population. There would be a rationale for public funding if a positive impact on productivity could be established and if some students were not mobile because of credit constraints. In this case public funding could on the one hand increase the participation in mobility programs and on the other hand the same students would repay the subsidies latter with taxes on their higher incomes (equivalent to fiscal rates of return on education). Second, these public funds are currently primarily benefiting those students who already have the personal financial means to afford such exchange semesters. This is, then, to a large extent, subsidization of students who are better off in a socio-economic sense and who would probably pay for their mobility with private funds if no subsidization was available.

The present situation certainly warrants further study of the effect of exchange semesters, in more detail and possibly from a longer-term perspective. Not least when considering the significance attached to exchange semesters by politicians, university leaders and the student body itself.

Acknowledgements The authors wish to thank the Swiss Federal Office for Statistics for permission to use the data of the Swiss University Graduate Survey and Sabine Schmidlin and Philipp Dubach for advice. We are particularly grateful to Stefan Denzler of the SKBF for his assistance in processing and revising the dataset. We also thank two anonymous referees and the Editor for their helpful comments and suggestions. Any remaining errors are the sole responsibility of the authors. 


\section{Appendix}

\section{Descriptive statistics}

\begin{tabular}{llll}
\hline Variables & Mean & Minimum & Maximum \\
\hline Exchange semesters (all) & 0.233 & 0 & 1 \\
Exchange semesters (accredited only) & 0.181 & 0 & 1 \\
Number of semesters (all) & 12.22 & 8 & 20 \\
Number of semesters (accredited only) & 12.36 & 8 & 20 \\
Female & 0.492 & 0 & 1 \\
Swiss & 0.924 & 0 & 1 \\
Mother's educational level (tertiary) & 0.091 & 0 & 1 \\
Resides in university canton & 0.568 & 0 & 1 \\
Age starting university & 23.08 & 17 & 35 \\
Vocational apprenticeship before university & 0.064 & 0 & 1 \\
Degree qualifying for secondary school teaching & 0.035 & 0 & 1 \\
Gainfully employed while studying (unrelated) & 0.335 & 0 & 1 \\
Gainfully employed while studying (related) & 0.154 & 0 & 1 \\
Gainfully employed while studying (related and unrelated) & 0.345 & 0 & 1 \\
Dummy for 2001 survey & 0.534 & 0 & 1 \\
Social sciences & 0.225 & 0 & 1 \\
Economic sciences & 0.172 & 0 & 1 \\
Exact sciences & 0.050 & 0 & 1 \\
Natural sciences & 0.174 & 0 & 1 \\
Humanities & 0.379 & 0 & 1 \\
University of Zurich & 0.335 & 0 & 1 \\
University of Bern & 0.197 & 0 & 1 \\
University of Basel & 0.123 & 0 & 1 \\
University of Freiburg & 0.103 & 0 & 1 \\
University of Geneva & 0.099 & 0 & 1 \\
University of Lausanne & 0.095 & 0 & 1 \\
University of Neuenburg & 0.048 & 0 & 1 \\
Unaly & &
\end{tabular}

\section{References}

ADMIT (2002). Higher education admissions and student mobility: The ADMIT research project. European Educational Research Journal, 1(1), 151-172.

Angrist, J., \& Krueger, A. B. (2001). Instrumental variables and the search for identification: From supply and demand to natural experiments. Journal of Economic Perspectives, 15(4), 69-86.

BBW (2002). EU-Programm ERASMUS. Studierendenaustausch, Dozierenden-austausch, Hochschulzusammenarbeit. 10 Jahre schweizerische Beteiligung 1992-2002, Schriftenreihe BBW 2002/2, Bern.

Behrmann, J. R., \& Rosenzweig, M. R. (2002). Does increasing women's schooling raise the schooling of the next generation? American Economic Review, 92(1), 323-334.

Frenette, M. (2006). Too far to go on? Distance to school and university participation. Education Economics, 14(1), 31-58.

Groot, W., \& Massen van den Brink, H. (2000). Overeducation in the labor market: A meta-analysis. Economics of Education Review, 19(2), 149-158.

Jahr, V., Schomburg, H., \& Teichler, U. (2002). Internationale Mobilität von Absolventinnen und Absolventen europäischer Hochschulen, Werkstattberichte Band 61, Kassel: Wissenschaftliches Zentrum für Berufs- und Hochschulforschung der Universität Kassel.

Leemann, R. J. (2002). Chancenungleichheit beim Übergang in eine wissenschaftliche Karriere. Schweizerische Zeitschrift für Bildungswissenschaften, 24(2), 197-222.

Maiworm, F., Steube, W., \& Teichler, U. (1991). Learning in Europe. The ERASMUS experience, a survey of the 1988-1989 ERASMUS students, Higher Education Policy Series 14, London: Jessica Kingsley Publishers. 
Maiworm, F., Steube, W., \& Teichler, U. (1993a). ERASMUS student mobility programmes 1989/ 1990 in the view of their coordinators, Werkstattberichte Band 41, Kassel: Wissenschaftliches Zentrum für Berufs- und Hochschulforschung der Universität Kassel.

Maiworm, F., Steube, W., \& Teichler, U. (1993b). Experiences of ERASMUS students 1990/1991, Werkstattberichte Band 42, Kassel: Wissenschaftliches Zentrum für Berufs- und Hochschulforschung der Universität Kassel.

Teichler, U. (1991). Experiences of ERASMUS Students. Select Findings of the 1988/1989 Survey, Werkstattberichte Band 32, Kassel: Wissenschaftliches Zentrum für Berufs- und Hochschulforschung der Universität Kassel.

Teichler, U. (1996). Student mobility in the framework of ERASMUS: Findings of an evaluation study. European Journal of Education, 31(2), 153-179.

Teichler, U., \& Jahr, V. (2001). Mobility during the course of study and after graduation. European Journal of Education, 36(4), 443-458.

Teichler, U., \& Maiworm, F. (1997). The ERASMUS experience, major findings of the ERASMUS evaluation research project. Kassel: Wissenschaftliches Zentrum für Berufs- und Hochschulforschung der Universität Kassel.

Teichler, U., \& Maiworm, F. (1994). Transitions to work: The experiences of former ERASMUS students. London: Jessica Kingsley Publishers.

Wolter, S., \& Zbinden, A. (2002). Labour market expectations of Swiss University Students. International Journal of Manpower, 23(5), 458-470.

Wooldrige, J. M. (2003). Introductory econometrics: A modern approach. Mason: Thomson South Western. 